\title{
Wat dateer ons? Enkele opmerkings rondom die datering van Bybelse tekste
}

\author{
C Lombaard \& J H le Roux \\ Departement Ou-Testamentiese Wetenskap \\ Universiteit van Pretoria
}

\begin{abstract}
What are we dating? Some remarks on the dating of biblical texts

When a date is ascribed to a Biblical text, it is at times unclear precisely what is being dated. Does the date relate so some historical event which may have occurred, or alternatively, is it projected into another era? Does it refer to the possible formation date of an oral tradition, or is it perhaps some phase in its development through history which is being dated? Is it the a quo date for when a text is judged to have been written down, or the date ad quem, or some process of rewriting - either between these two dates, or possibly some minor editorial alteration after the ad quo date - which is to be given? Is it referring to a time when an interpretative frame was placed around existing text? This article provides an overview of what it is about a text that may be dated. It concludes with an appeal for greater accuracy of formulation in the already precarious matter of dating biblical texts.
\end{abstract}

\section{DATERINGSPROBLEME TANS}

Spesifiek die Ou-Testamentiese wetenskap is die afgelope jare ernstig geraak deur ingrypende voorstelle rondom die datering van tekste van die Ou Testament. Hierdie is nie 'n nuwe verwikkeling in die sin dat die datering van tekste ooit in die geskiedenis van die kritiese wetenskap as afgehandel beskou is nie. Daar was egter sedert Wellhausen $\left(1963^{4}\right)$ se invloedryke werk aan die einde van die negentiende eeu tot die 1970s toe nog tot 'n groot mate 'n sekere "normale" stand van wetenskap, in Kuhniaanse sin (kyk Kuhn 1962). Hierdie relatief bestendige stand van sake het behels dat spesifiek die tradisionele vier bronne of lae van die Pentateug se datering min of meer gegewe as aanvaar is. Tot 
'n groot mate het die datering van die res van die Ou Testament ook hiermee verband gehou. Die baken-datums van die vroeë koningskap (waarmee die Jahwis in verband gebring is), die effens latere koningskap (waarmee die Elohis - ten spyte van die probleme om tussen die Jahwistiese en Elohistiese tekste te onderskei - geïdentifiseer is), die Josiaanse hervormings (waarmee die vroegste aanvang van die Deuteronomistiese beweging, invloedryk, reeds deur De Wette 1806:265ev ${ }^{1}$ geassosieer is) en die Babiloniese ballingskap (waarmee die hoogbloei van die Deuteronomistiese redaktorsaktiwiteite en die aanvang van die Priesterskriftelike aktiwiteite saamhang), was vir dekades as paradigmamerkers aanvaar. Die datering van Ou Testamentiese tekste relatief tot mekaar was dus tot 'n hoë mate stabiel en seker.

Die teenreaksie op die histories-kritiese lees van die Ou Testament sedert die 1970s het nie die karakter gedra dat dit hierdie bakendatums op enige dramatiese wyse hersien het nie. Eerder was dit die geval binne hierdie teenreaksie-stroom dat a-historiese eksegetiese benaderings ontwikkel is as alternatiewe tot die histories-kritiese benaderings. Hierdie nuwere eksegetiese benaderings het ingesluit die verskillende skole van strukturalisme ${ }^{2}$, die narratiewe benadering (bv Marguerat \& Durrer 1999), en die verskillende "bevrydingslesings" van die Bybelse teks (hieronder kan gereken word, plaaslik, met onder andere Boesak 1984; vgl West 1995:60-82).

Hierdie benaderings tot Bybeluitleg, so belangrik as wat hulle was en blý, het egter nooit daarin geslaag om die historiese lesings te vervang nie, ten spyte van redelik

\footnotetext{
1 Davies (1992:40-41) vind die datering gebaseer op De Wette se teorie te sirkulêr vir wetenskaplike aanvaarding. De Wette se teorie is egter, soos enige ander, 'n hipotese wat gestel is en kritiese bevraagtekening moes weerstaan. Dít is inderdaad die aard van hipotese- of teoriebou, 'n fundamentele aspek van die wetenskaplike proses. Davies se kritiek is hier gegrond op sy basis-kriterium van argeologiese oftewel buite-Bybelse verifieerbaarheid - 'n legitieme aanspraak, maar een wat nie alleenreg op wetenskaplikheid het nie. Soos Rowley (1952:259) reeds gewaarsku het: buite-tekstuele gegewens soos inligting uit die paleografie of argeologie kan nie alléén, dit is buite-om binne-tekstuele gegewens vertrou word om datering te bepaal nie. Anders gestel: argeologie kan nie eksegese vervang nie. Komplementering is duidelik die meer gebalanseerde benadering. Vandaar dat bv Otto (2000:3 \& 234) steeds groot waarde kan heg aan dié teorie van De Wette. Dit is instruktief op hierdie punt om daarop te let dat die debat in die middel van die vorige eeu rondom die datering van die Dooie See rolle sterk parallelle toon met die huidige dateringsdebat onder Ou Testamentici. Intense meningsverskil en persoonlike aanvalle, selfs aanklagte van vervalsing - dat moderne namaaksels as antieke fondse voorgestel is, het die gesprek tussen dié met "adventurous haste" en dié met "extreme caution" gekenmerk (Rowley 1952:257-259). Moontlik staan die tweespalt tans tussen die sogenaamde minimaliste en die maksimaliste dus tot 'n sekere mate in die teken van die relatiewe varsheid van die nuwere herdateringsvoorstelle?

2 Lombaard (1998:203 \& 2001:4685) onderskei die volgende invloedryke skole van strukturalisme: die Franse strukturalisme (wat direk teruggaan op veral die Cours de linguistique générale van F. de Saussure), die Amsterdamse skool (kyk Oost 1986), die Richter Schüle in Duitsland (kyk bv Richter 1971), die Claremont-skool in die VSA (kyk bv Knierim 1992, die vader van Claremont strukturalisme, en die opstelle van Knierim se studente in Sun \& Eades 1997) en, plaaslik, die Pretoria-skool van strukturalisme (kyk bv Loader 1978:1-40; Prinsloo 1988, asook hulle studente, bv Coetzee 1986; Viviers 1990).
} 
gereelde aansprake daartoe. Die vrae van die historiese wetenskap kon gewoon nie deur hierdie benaderings beantwoord word nie, en kon ook nie ontken word nie. Die historieskritiese eksegese van die Bybel bly dus steeds die hoofstroom-benadering en lewer steeds die belangrikste resultate.

Omstreeks dieselfde tydperk wat die a-historiese eksegetiese metodes hul invloed voelbaar gemaak het, het daar binne histories-kritiese kringe ook vrae begin ontstaan rondom die tradisioneel-aanvaarde datering van die Ou Testamentiese literatuur. Navorsers soos Veijola (1977), Van Seters (1983), Lemche (1988) en Thompson (1999) die soge-naamde Kopenhagen-skool -, Davies (1992) en Whitelam (1996) - die sogenaamde. Sheffield-skool -, Blum (1990), Braulik (1991) en Otto (2000) het die geskiedenis van individuele tekste en van redaksionele lae in die Ou Testament anders begin ontleed of meet, onder andere ook aan argeologiese kriteria. Sodoende is tot gevoltrekkings omtrent die datering van die tekste gekom wat verskil het van dié in die voorafgaande dekades. Hierdie pogings het uitgeloop op radikale herdateringsvoorstelle, wat onder andere insluit dat die Jahwis uit die middel tiende eeu vervang word met 'n Jerusalemse Geskiedwerk uit die eerste helfte van die sewende eeu (vgl Zenger 1995:167-172), dat die meeste van die Ou Testamentiese literatuur uit die vyfde tot derde eeu stam (Davies 1992:76), of dat die ganse Ou Testament as 'n Hellenistiese dokument gelees gesien moet word (Lemche; kyk Scheffler 1998:523).

Daar was wye reaksie op hierdie herdateringsvoorstelle. Debatte in die meer populêre media het openlik vurig geword, byvoorbeeld in die Biblical Archaeological Review (Davies en Dever in Davies 2000:24-27; 28-35, en Dever, Lemche, Thompson en McCarter in Shanks 1997:26-42) en in vakgerigte Internet-nuuslyste soos IOUDAIOS en http://groups.yahoo.com/group/biblical-studies het van die protagoniste, en ook hulle ondersteuners en teenstanders, se woorde soms heet geword. Dié debat duur steeds voort, soms ewe vurig (kyk http://www.bib-arch.org/bswb_BAR/bswbBARFeature2.html; laas nagegaan op 9 April 2002). Ook plaaslik het die debat sy uitwerking gehad in publikasies soos dié van Scheffler (1998:522-533) en Le Roux (1998:477-486), asook in talle gesprekke tydens kongresse en ander byeenkomste van vakgenote.

Die debat in die Nuwe Testamentiese wetenskap is nie in die onlangse verlede geraak deur soortgelyke drastiese herwaarderings van die tradisioneel-aanvaarde datering van tekste nie. Die meer opspraakwekkende bevindings rondom die historiese Jesus vanuit byvoorbeeld die geledere van die Jesus Seminar (Witherington 1995 gee 'n substansiële oorsig van dié "derde beweging" tot en met 1994; 'n nuwer navorsingsoorsig is te vinde by Porter 2000) maak van, byvoorbeeld, buite-Bybelse tekste gebruik (vgl bv 
Evans 1996:256-299), eerder as dat Bybelse tekste dramaties herdateer word. Tog is die Nuwe-Testamentiese wetenskap nie onaangeraak deur minstens pogings tot herdatering, soos om die algemeen-aanvaarde Markaanse prioriteit onder die evangelies uit te daag, nie $^{3}$. In 'n beperkte sin raak die vrae wat hier gestel word, die Nuwe-Testamentiese wetenskap tans dus minder akuut as wat dit die geval is met die Ou-Testamentiese wetenskap tans. Tog bly die grondprobleem wat hierdie artikel aanraak ewe toepaslik op beide Testamente. Hierdie vraag is naamlik nie in die eerste plek na die datums wat aan tekste toegeken word nie, maar 'n meer fundamentele vraag: wat is dit wat gedateer word?

Die sentrale vraag hier is dus na die aard van die "teks" wat gedateer word. ${ }^{4}$ Die datering waartoe ook al gekonkludeer word deur navorsers, is dus nie die onderwerp hier nie, hoewel die resente dateringsdebatte duidelik aanleiding gee tot hierdie besinning 5 . Die vraagstelling hier is 'n meta-vraag. Ter wille van 'n duideliker debat, waarin soortgelykes met mekaar vergelyk word en waarin deelnemers aan die gesprek mekaar dus beter kan begryp, word die tipe "teks" wat telkens gedateer word, aan die orde gestel.

3 Vergelyk hiervoor byvoorbeeld die 1998-uitgawe van The International Bible Commentary, spesifiek Dungan \& Kloppenburg (1998:1235-1237) se bydrae daarin, asook dié van ander bydraers vanuit die Noord-Amerikaanse konteks wat ook minstens aanduidings gee dat hulle 'n Matteaanse prioriteit steun. (Dit blyk egter dat dié siening in ander vertalings van hierdie eenvolume-kommentaar uitgeredigeer word.)

${ }^{4}$ Die term "teks" word hier aangewend soos wat dit gebruiklik geword het in die filosofiese hermeneutiek en die semiotiek, naamlik dat enige saak wat om interpretasie vra, as "teks" benoem word. "Teks" kan dus insluit orale vertellinge, geskrifte, argeologiese artefakte en dies meer.

${ }^{5}$ Hulpmiddels vir datering sluit onder andere in:

- Historiese oorwegings, altyd gebaseer op rekonstruksies van die geskiedenis;

- Argeologiese artefakte en argeologiese vergelyking, wat beide ook interpretatiewe omgang met sodanige materiaal verg (bv die sg. Baltimore- of Albright/Bright-skool, wat minder krities met die teks van die Ou Testament omgaan en meer waarde aan die "bewyswaarde" van die argeologie heg, teenoor die sg. Leipzig- of Alt/Noth-skool, wat historiese rekontruksies van die teks ernstiger neem en meer krities-interpreterend met die argeologie omgaan - 'n onderskeid wat steeds 'n uitwerking het; vgl Bartlett 1997:7 \& Laughlin 2000:3-16);

- Filologiese en ander taalkundige oorwegings, wat ook nie sonder opset is nie (vgl bv Tyler 1990 met bv Rendsburg 1990), sodat bv Davies (1992:102-105) - waarskynlik te skepties - daarom die waarde van súlke studies vir historiografie bevraagteken;

- Teologiese en godsdienshistoriese ontwikkelinge, sodat sodanige "trajekte" binne die Bybelse tekste gepeil kan word (vgl Walsh 1984:13-19). "Ontwikkeling" impliseer nie hier "vooruitgang" soos wat dit in bv die negentiende eeuse wetenskapsfilosofie van Hegel, of in 'n sekere konsep van "heilsgesiedenis" na vore kom nie (vgl Ollenburger 1992:6-15). Eerder beteken "ontwikkeling" hier aanpassing en verandering na gelang van die sosio-historiese en teologiese milieu in samehang met die retoriese opset van die skrywer (vgl bv die "Dag van die Here"-konsep in die Ou Testament soos geanaliseer in Le Roux 1986:136-144.)

- Vergelykende literatuur: óf binne-Bybels (bv De Wette 1806), óf met kanonies-verwante tekste (soos die Qumran-tekste), óf met buite-Bybels invloed (kyk bv Albertz 1992:497-504 in navolging van Blum 1990). 


\section{WAT WORD GEDATEER?}

Vervolgens word vyf moontlike sake wat dateer word, elk kortliks bespreek. Voorbeelde word waar toepaslik ter verheldering veskaf.

\subsection{Dateringsmoontlikheid 1: Die datum gekoppel aan 'n teks as verwysing na 'n historiese gebeurtenis of verwikkeling}

Met hierdie eerste dateringsopsie word die werklike historiese gebeure en die daarmeeverbandhoudende opeenvolging van gebeure nagespeur, in soverre as wat dit moontlik is. Die duidelikste voorbeeld hiervan in die kritiese navorsingsgeskiedenis van die Bybelwetenskappe is waarskynlik die sogenaamde Leben Jesu Forschung. Die aanvangspunt van die navorsing rondom die sinoptiese probleem was naamlik die belangstelling om die gebeurlikhede in die lewe van Jesus van Nasaret so ver moontlik histories en chronologies vas te stel (kyk bv Hurth 1989). Daarmee saam gaan ook die datering van gebeurebeskrywings waartoe gekonkludeer word dat dit nie meer aan die historiese Jesus verbind kan word nie. Dieselfde behoefte kom, hoewel andersoortig, ook tot uitdrukking in die tweede en derde oplewings in navorsing oor die historiese Jesus. ${ }^{6}$ Die punt van datering hier is dus: wanneer het wat gebeur? Vir ons doeleindes hier geld dít as die eerste manier waarop datering in die Bybelwetenskappe na vore kom.

\subsection{Dateringsmoontlikheid 2: Die tydperk waarin'n teks sigself plaas versus die tydperk waarin die teks tot stand gekom het}

Naas die gebruik van Bybeltekste om historiese gegewens daaruit af te lei, is daar ook die verskynsel dat 'n teks sélf voorgee om uit 'n sekere tydperk te dateer, terwyl dit in der waarheid uit 'n gans ander tydperk kom. Die klassieke voorbeeld hiervan is die boek Daniël, wat sigself plaas binne die tydperk van die Babiloniese ballingskap (586-539 vC), maar waarvan die skriftelike oorsprong, behalwe in meer konserwatiewe kringe, sedert die 19de eeu algemeen as tweede-eeus voor Christus aanvaar word. ${ }^{7}$ Natuurlik het ook dié teks 'n ingewikkelde redaksionele proses deurloop (kyk bv Collins 1993:24-38). Vir ons doeleindes hier is die punt egter dat, in den breë, die boek Daniël sigself in die Babiloniese ballingskapstydperk plaas, terwyl dit in werklikheid in die tyd van die

\footnotetext{
6 Die sogenaamde "laat-dateerders" van die Ou Testament se werkswyse is andersoortig, naamlik om die nasporing van veral die pre-eksiliese en eksiliese geskiedenis van Israel te problematiseer.

7 Die boek Openbaring keer weer hierdie verwysingsrigting om: deur die leser na die toekoms te verplaas, word iets oor die hede van die leser gesê (vgl bv Du Rand 1990:199-207).
} 
Seleukidiese heerskappy ontstaan het. As daar dus hier van datering sprake is, is duidelikheid nodig oor watter van die twee eras ter sprake kom: die vertelde tyd (dus middel-sesde eeus) of die ontstaanstyd (dus middel-tweede eeus). In die boek Jona word 'n soortgelyke situasie aangetref (vgl Eynikel 2001:1323-1328); vir verskillende redes is Jona egter binne die Suid-Afrikaanse gemeenskap méér kontroversieel (kyk Lombaard 2002:120-128). Watter van hierdie twee moontlikhede - vertelde tyd of ontstaanstyd deur navorsers gedateer word, moet dus telkens duidelik uitgespel word. ${ }^{8}$ Ontstaansdatum en vertelde milieu is dus hier, soos met 'n moderne historiese roman, nie dieselfde saak nie, en onakkurate dateringsformulerings deur navorsers kan wanvoorstellings veroorsaak.

\subsection{Dateringsmoontlikheid 3: Die ontstaanstyd van 'n orale tradisie, of 'n latere moment in die ontwikkelingsgeskiedenis daarvan?}

Reeds vir meer as twee eeue word dit as 'n gegewe binne die Bybelwetenskappe aanvaar dat baie van die skriftelike neerslag in die Bybel voorafgegaan is deur mondelinge oorleweringe. Voorbeelde wat invloedryk in die wetenskapsgeskiedenis van die vakgebiede Nuwe Testament en Ou Testament onderskeidelik was, is onder andere die nagmaalswoorde van Jesus (Mark 14:22-26; 1 Kor 11:23-26; Matt 26:26-29; Luk 22:1420; Justinius, 1 Apologia 66) en die "my vrou - my suster"-passasies (Gen 12:10-20; 20:1-18; 26:1-11). Die probleem hier ontstaan as navorsers gewoon na die "orale fase" wat agter 'n spesifieke teks lê, verwys, asof dit 'n genoegsame dateringsaanduiding is. Is die implikasie egter dan dat die orale fase tot 'n hoë mate die outentieke woorde van om bostaande voorbeeld weer op te neem - Jesus met die instelling van die nagmaal sou reflekteer? Indien hierdie implikasie gelaat word, en daarmee gepaardgaande die indruk by die leser gewek word dat die nagmaalswoorde wel tot op Jesus van Nasaret teruggaan, word 'n datering van vroeg in die dertigerjare van die Christelike era geïmpliseer. Terselfdertyd word dan die vraag of die nagmaalswoorde wél tot op Jesus teruggaan, en indien nie, die vraag na die moontlike werklike ontstaanstydperk(e) van die nagmaalswoord-tradisie, vermy. Die speling van drie dekades en meer wat by hierdie NuweTestamentiese voorbeeld ter sprake kom, rek tot veel groter dimensies as voorbeelde

\footnotetext{
${ }^{8}$ Davies (1992:24-25), byvoorbeeld, maak in sy soeke na 'n "suiwer feitelike" kriterium vir navorsing oor antieke Israel hierdie "verplaasde tyd" van toepassing op al die Ou Testamentiese literatuur wat preeksiliese gebeure verhaal.
} 
vanuit die $\mathrm{Ou}$ Testament, met sy chronologies meer substansiële orale agtergrond, gehaal word.

Die vraag na datering hier fokus dus op die kwessie of 'n pre-tekstuele datering verwys na die ontstaanstyd van 'n mondelinge oorlewering, of na 'n sekere fase daarvan, naamlik - gewoonlik - kort voordat dit op skrif gestel is. Daarmee saam moet ook in gedagte gehou word dat verskrifteliking nie oraliteit beëindig nie: dié twee modi van tradisie-oordrag het waarskynlik in die meeste gevalle vir 'n tyd lank naas mekaar gefunksioneer, met wedersydse beïnvloedings- en interpretasiemoontlikhede. Laasgenoemde gegewe maak die datering van 'n orale tradisie nie alleen meer moontlik as wat kritici van die datering van mondelinge tradisies dit wil hê nie, maar verhoog ook die noodsaak vir akkurate formulering: is dit die ontstaan van die orale tradisie of die (pas)voorskriftelike fase daarvan wat gedateer word?

\subsection{Dateringsmoontlikheid 4: Die datering van die skriftelike neerslag: $a$ quo, ad quem of quo inter?}

Dikwels wanneer die datering van spesifiek Ou Testamentiese tekste aangebied word, met hulle meer uitgebreide redaksionele geskiedenis as wat die geval is met Nuwe Testamentiese tekste, bly dit onduidelik na presies watter fase van die teks in die ontwikkelingsgang daarvan verwys word. In die geval van die redaksionele bron/laag D in die Enneateug (Gen tot 2 Kon 24), byvoorbeeld, word die onderskeid gewoonlik getref tussen die dokument wat tydens die Josiaanse hervormings "gevind" is (bestaande uit Deut 12-26, soos verhaal in 2 Kon 22:3-23:3 - die steeds invloedryke hipotese van De Wette 1806), die Deuteronomistiese Geskiedenis (dit wil sê die boeke Deut tot 2 Kon soos wat dit tydens die ballingskap in Babilonië saamgestel en verwerk is), en redaksionele werk aan ander tekste soos die profete, wat vanuit die Deuteronomistiesteologiese denkskool tydens en na die ballingskap aangebring is. Wanneer egter bloot na " $\mathrm{D}$ " in die vakliteratuur verwys word, is dit soms moeilik om te bepaal presies wat die outeur tans in gedagte het. Die feit dat die datering, ekstreem gestel, sou kon wissel van die Josiaanse hervormings in die voorlaaste dekade van die sewende eeu, tot - as Deuteronomisties-teologiese invloede nagetrek word - die afsluiting van die Daniël-boek rondom $164 \mathrm{vC}$, met die grootste Deuteronomistiese redaksionele aktiwiteit tydens en net 
ná die ballingskap (dus in die tweede helfte van die sesde eeu), laat 'n wye speelruimte. Die noodsaak hier is dus, weer eens, dat akkuraat geformuleer word: word daar na die vroegste moontlike D-dokument (Deut 12-26*), of die latere eksiliese Deutoronomistiese Geskiedwerk en redaksionele hersienings, of die daaruit-ontspringende verdere teologiese invloede verwys? Gewoonlik minder dramaties, maar altyd toepaslik, kom die volgende vraag telkens met die datering van 'n teks ter sprake: is dit die a quo, quo inter of ad quem verskriftelikings- of redaksionele datum wat aangebied word?

\subsection{Dateringsmoontlikheid 5: Die finale gestaltegewing van die teks}

Die uitdrukking "finale gestaltegewing van die teks" sou óf na die finale redaksionele werk aan 'n teks, óf na die plasing daarvan binne 'n nuwe geheelkonteks kon verwys. Eersgenoemde moontlikheid is reeds hierbo bespreek. Waarna hír verwys word, is die plasing van 'n min-of-meer afgeslote teks binne 'n groter verband of raamwerk. Hierdie "omramingsproses" sluit altyd minstens 'n tekstuele en sosio-historiese konteks in. Hiermee word bedoel dat die plasing van 'n nuwe raamwerk rondom 'n bestaande teks of tekskompleks nie alleen ' $n$ herinterpretasie van die teks beteken nie, maar terselfdertyd ook ' $\mathrm{n}$ hertoepassing daarvan. Laasgenoemde verwys na die plasing of tuisbring van die nuwe teksgeheel binne die nuwe, veranderde sosio-historiese konteks, naamlik dié van die betrokke redaktor.

So byvoorbeeld het die plasing van die Dekaloog binne die Sinai-konteks, van die Genesis-skeppingstekste binne Pentateug- en Enneateug-verband, en ook die insluiting van die verskillende Bybeltekste binne 'n kanon wat mettertyd die Ou en Nuwe Testamente behels (in verband met laasgenoemde was veral Childs 1979 invloedryk; vgl ook Barr 1981:32-36), telkens implikasies op vier dimensies:

- die betekenisdimensies van die kleiner teks;

- die skopus en betekenisdimensies van die nuwe, groter teksgeheel;

- die verstaan van die teks en daaruit voortvloeiend die selfverstaan van die bedoelde lesersgemeenskap waarbinne of vir wie dié nuutplasing geskied; en

- die lesersgemeenskappe wat mettertyd binne die Wirkungsgeschichte van die teks te staan kom. 
Die pleidooi hier is dus vir 'n spesifieke dateringsaanduiding vir hierdie omramingsproses, waar dít is wat die navorser in die oog het. Die datering van die kleiner teks en dié van die groter geheelteks is nie dieselfde nie; laasgenoemde bly bykomende redaksionele arbeid, al is dit redaksionele werk in breë trekke, naamlik deur "omraming". Waar lesers nie spesifiek daarop gewys word dat dit híerdie omramingsproses is wat tans gedateer word nie, skep dit die moontlikheid tot misverstand, naamlik dat die teks verstaan word as sou dit uit die omramingstydperk stam, terwyl die samestellende teksdele inderdaad veel ouer is.

Laasgenoemde het nie ten doel om die geldigheid van interpretasie-historiese studies, dit wil sê die nagaan van hoe ouer tekste in 'n latere tyd - soos so 'n omramingstydperk - verstaan is, in twyfel te trek nie. Die teksimmanente studie van 'n teks binne 'n spesifieke historiese wordingstadium is inderdaad belangrik. Die historiese gaan egter die immanente vooraf ('n ommekeer van die tradisionele aanpak van die Pretoria-skool van struktuur-analise; vgl Lombaard 1996:106-113), en word nie daardeur opgehef nie. Dateringsaanduidings behoort hierdie saak met omsigtigheid in berekening te bring.

\section{SAMEVATTING}

Sodra 'n gebeutenis gebeur het, is dit vir goed verby. Om dit talig te maak, onder andere deur historiografie, herstel nie die gebeurtenis in die hede nie, maar herroep dit gederiveerd (sekondêr, tersiêr, ens), dus veranderd. Taal kan geskiedenis nie vasvang of herhaal nie; die geskiedenis bly verby; die verlede bly buite ons direkte bereik. Dieselfde geld verskrifteliking. Sodra 'n vertelling of mondelinge oorlewering neergepen word, is dit reeds weer veranderd. Die nuwe medium het 'n dinamika wat verskil van die vorige. Tussen die pen en die mond val veel op die grond, en veel nuuts word opgetel ook. Op letters kan ons dus ewe min vertrou as op klanke (oraliteit) om geskiedenis "waar", "korrek", "akkuraat", "getrou" aan ons te bemiddel. Die feit dat die voor-moderne outeursbeskouing tekstuele veranderinge as 'n natuurlike kontekstualiserende proses aanvaar het, bemoeilik ons wetenskaplike lees van die antieke Bybelse tekste des te meer (kyk Lombaard 2002:97, 121 vir enkele perspektiewe op hierdie verskillende outeurskapsienings toegepas op Bybelse tekste). Redaksionele werk aan en omraming van sommige Bybeltekste het die kompleksiteit daarvan verhoog, soms tot bokant ons teoretiese vuurmaakplek. 
Vandaar dat, in soverre as wat dit bepaalbaar is, én steeds binne die onderskeie teoretiese benaderings, presiese beskrywing van hierdie tekste vir die behoeftes van wetenskaplike debat onontbeerlik is. Hierdie presiese bekrywing sluit in analise van die teks en die karakterisering van die samestellende dele/"tekste" as byvoorbeeld mondelinge oorlewering of redaksionele bewerking. Waar die datering van hierdie geamalgameerde tekste ter sprake gebring word, is dit daarom belangrik om duidelik te stel wat dit is wat tans gedateer word. Is dit die historiese gebeurtenis onder bespreking waaraan 'n datum gekoppel word? Is dit die tydvak waarin die vertelling sigself plaas, of die tydperk waarin die betrokke skrywer/redaktor hierdie plasing onderneem? Of moontlik ' $n$ fase in die mondelinge of skriftelike herinnering aan of skepping van gebeure? Of die aanwending van 'n teks wat reeds sy eie ontwikkelingsgeskiedenis deurloop het, maar wat nou binne 'n nuwe redaksionele raamwerk geplaas word ten einde daaraan sekere vars betekenismoontlikhede te verleen?

Hierdie en vele ander moontlikhede kom in die spel van eksegese (terminologie ontleen aan Le Roux 1996:41-56) na vore. Ter wille van samehangende debat tussen vakwetenskaplikes, ook ter wille van duidelikheid vir spesialiste uit ander vakgebiede en vir sinvolle gebruik van Bybelnavorsing deur predikante en dies meer, bly akkurate aanduiding van wat dit is wat gedateer word, van groot belang.

\section{Literatuurlys}

Albertz, R 1992. Religionsgeschicte Israels in alttestamentlicher Zeit, Vol 2. Göttingen: Vandenhoeck \& Ruprecht

Barr, J 1981. The Bible as a document of believing communities, in Betz, H D (ed), The Bible as a document of the university, 25-47. Chico, CA: Scholars Press.

Bartlett, J R 1997. What has archaeology to do with the Bibel - or vice versa?, in Bartlett, J R (ed), Archaeology and biblical interpretation, 3-13. London: Routledge.

Blum, E 1990. Studien zur Komposition des Pentateuch. Berlin: De Gruyter.

Boesak, A A 1984. Black and Reformed: Apartheid, liberation and the Calvinist tradition. Johannesburg: Skotaville Press.

Braulik, G 1991. Die deuteronomischen Gesetze und der Dekalog: Studien zum Aufbau von Deuteronomium 12-26. Stuttgart : Katholisches Bibelwerk. 
Childs, B S 1979. Introduction to the Old Testament as Scripture. London: SCM Press.

Coetzee, J H 1986. Die spanning tussen God se "verborge wees" en sy "ingrype om te red": 'n Eksegetiese ondersoek na 'n aantal klaagpsalms. DD-proefskrif, Universiteit van Pretoria.

Collins, J J 1993. Daniel. Minneapolis: Fortress. (Hermeneia.)

Davies, P 2000. What separates a minimalist from a maximalist? Not much. Biblical Archaeology Review 26(2), 24-27.

Davies, P R 1992. In search of "ancient Israel". Sheffield: Sheffield Academic Press. (JSOT Supplement Series 148.)

De Saussure, F 1922. Cours de linguistique générale. Paris: Payot.

Dever, W G 2000. Save us from postmodern malarkey. Biblical Archaeology Review 26(2), 28-35.

De Wette, W M L 1806. Beiträge zur Einleitung in das Alte Testament, I: Kritischer Versuch über die Glaubwürdigkeit der Bücher und Gesetzgebung. Halle.

Du Rand, J A 1990. Johannese perspektiewe. Johannesburg: Orion.

Dungan, D L \& Kloppenburg, J S 1998. The synoptic problem: How did we get our Gospels?, in Farmer, W R (ed.) The International Bible Commentary, 1231-1240. Collegeville, MN: The Liturgical Press.

Evans, C A 1991. Life of Jesus research: An annotated bibliography. Leiden: E J Brill.

Eynikel, E 2001. Jona, in Eynikel, E, Noort, E, Baarda, T \& Denaux, A (reds) Internationaal commentaar op de Bijbel, 1323-1328. Kampen: Kok.

Hurth, E 1989. In his name: Comparative studies in the quest for the historical Jesus. Frankfurt am Main: Peter Lang.

Kuhn, T S 1962. The structure of scientific revolutions. Chicago: University of Chicago Press.

Knierim, R P 1992. Text and concept in Leviticus 1:1-9: A case in exegetical method. Tübingen: J C B Mohr (Paul Siebeck). (Forschungen zum Alten Testament 2.)

Lauchlin, J C H 2000. Archaeology and the Bible. London: Routlegde.

Lemche, N P 1988. Ancient Israel: A new history of Israelite society. Sheffield: JSOT Press. 
Le Roux, J H 1986. Tekste met 'n profetiese perspektief, in Deist, F \& Vorster, W Woorde wat ver kom, 123-157. Kaapstad: Tafelberg. (Die literatuur van die Ou Testament, Deel 1.)

Le Roux, J H 1996. Eksegese is 'n spel. Acta Theologia 16(1), 41-56.

Le Roux, J H 1998. Israel's past and the feeling of loss (Or: Deconstructing the minimum of the minimalists even further). OTE 11(3), 477-486.

Loader, J A 1978. Gedagtes oor gekontroleerde eksegese. HTS 34, 1-40.

Lombaard, C J S 1996. 'n Nota op die aanwending van "tradisies" in die SuidAfrikaanse struktuuranalitiese eksegese van die Ou Testament. Skrif en Kerk 17(1), 106-113.

Lombaard, C J S 1998. Book review: Jonker, Louis C 1996. Exclusivity and variety: Perspectives on multidimensional exegesis. Kampen: Kok Pharos Publishing House. OTE 11(1), 199-203.

Lombaard, C J S 2001. Four recent works on the interpretation of the Old Testament in South Africa, with evaluation and some implications. Scriptura 78, 467-478.

Lombaard, C J S 2002. Ontmoet die profete van die Ou Testament, in Human, D \& Lombaard, C Vertellers en visionêre, 83-140. Braamfontein: NPK/Lyceum/ Damelin Education Group.

Marguerat, D \& Durrer, M 1999. How to read Bible stories: An introduction to narrative criticism. London: SCM.

Ollenburger, B C 1992. From timeless ideas to the essence of religion: method in Old Testament theology before 1930, in Ollenburger, B C, Martens, E A \& Hasel, G F (eds), The flowering of Old Testament theology: A reader in twentieth-century Old Testament theology: 1930-1990, 3-19. Winona Lake: Eisenbrauns.

Oost, R 1986. Omstrede Bijbeluitleg. Kampen: J.H. Kok

Otto, E 2000. Das Deuteronomium im Pentateuch und Hexateuch: Studien zur Literaturgeschichte von Pentateuch und Hexateuch im Lichte des Deuteronomiumrahmens. Tübingen: J C B Mohr. (Forschungen zum Alten Testament 30.)

Porter, S E 2000. The criteria for authenticity in historical-Jesus research: Previous discussion and new proposals. Sheffield : Sheffield Academic Press.

Prinsloo, W S 1988. Van kateder tot kansel: 'n Eksegetiese verkenning van enkele Psalms. Pretoria: NG Kerkboekhandel. 
Richter, W 1971. Exegese als Literaturwissenschaft: Entwurf einer alttestamentliche Literaturtheorie und Methodologie. Göttingen: Vandenhoeck \& Ruprecht.

Rowley, H H 1952. The internal dating of the Dead Sea scrolls. Louvain: Publications Universitaires de Louvain. (Analecta Lovaniensa Biblica et Orientalia, Ser. II, Fasc. 30.)

Scheffler, E 1998. Debating the late dating of the Old Testament. OTE 11(3), 522-533.

Shanks, H 1997. Face to face: Biblical minimalists meet their challengers. Biblical Archaeology Review 23(4), 26-42.

Sun, H T C \& Eades, K L (eds) 1997. Problems in biblical theology: Essays in honor of Rolf Knierim. Grand Rapids: William B Eerdmans.

Thompson, T L 1999. The Bible in history: How writers create a past. London: Jonathan Cape.

Tyler, L R 1990. The language of Ecclesiastes as a criterion for dating. Ann Arbor: UMI Dissertation Service.

Van Seters, J 1983. In search of history: Historiography in the ancient world and the origins of biblical history. New Haven: Yale University Press.

Veijola, T 1977. Das Königtum in der Beurteilung der deuteronomistischen Historiographie: Eine redaktionsgeschichtliche Untersuchung. Helsinki: Suomalainen Tiedeakatemia.

Viviers, H 1990. 'n Teksimmanente ondersoek na die samehang van die Macalot-Psalms (Pss 120-134). DD-proefskrif, Universiteit van Pretoria.

Walsh, R G 1984. Dating the New Testament: the methodological relevance of theological criteria. Ann Arbor: UMI Disseration Information Service.

West, G 1995. Biblical hermeneutics of liberation: Modes of reading the Bible in the South African context. Maryknoll: Orbis Books.

Whitelam, K 1996. The invention of ancient Israel: The silencing of Palestinian history. London: Routledge.

Wellhausen, J 1963. Die composition des Hexateuchs und der historischen Bücher des Alten Testaments. Berlin: De Gruyter

Witherington, B 1995. The Jesus Quest: The third search for the Jew of Nazareth. Downers Grove: InterVarsity Press.

Zenger, E (Hrsg.) 1995. Einleitung in das Alte Testament. Stuttgart: Kohlhammer. 